\title{
PROTOTIPE PERANGKAT NOTIFIKASI UNTUK SMARTPHONE BERBASIS ARDUINO PRO MICRO
}

\author{
Asep Saefullah ${ }^{1}$ \\ Mochamad Ibnu Safari ${ }^{2}$ \\ Handri Samanta ${ }^{3}$ \\ Email: asep.saefullah@raharja.info,ibnu.safari@raharja.info,samanta@raharja.info
}

Diterima : 26 Desember 2014 / Disetujui : 02 Februari 2015

\begin{abstract}
The widespread use of smartphones in all societies make increasing demands of smartphone accessories tools for ease of its use in everyday life. As if the user is in public, attending a meeting, or are driving a motor vehicle. Apart from the rapid use of smartphone technology on society, there is also the technology in the field of microcontroller that can be said to be rapid development in people's daily life, namely that a module arduino microcontroller. Therefore, we need a microcontroller-based devices that can help the user to display the condition of smartphones such as the presence of incoming messages or incoming calls to the smartphone, small size and can be implemented in accordance with the user's work. By using prototypes in the process of designing a simple model that can represent the actual future results and methods of the blackbox for testing this tool to determine whether the software and hardware to work properly and has been as expected. Can produce a device that functions as a media notification for smartphones such as short messages and incoming calls, and has an interface OLED Display. It can help users Smartphone in everyday life.
\end{abstract}

Keywords: Smartphone, Notifications, Arduino

\begin{abstract}
ABSTRAK
Maraknya penggunaan smartphone pada semua kalangan masyarakat membuat meningkatnya tuntutan alat-alat aksesoris smartphone untuk kemudahan dalam penggunaanya dalam kehidupan sehari-hari. Seperti jika pengguna sedang ditempat umum, mengikuti rapat, ataupun sedang berkendara kendaraan motor. Selain dari pesatnya penggunaan teknologi smartphone pada masyarakat, ada juga teknologi di bidang mikrokontroller yang dapat dikatakan pesat perkembangannya dalam kehidupan sehari-hari masyarakat, yaitu arduino yang merupakan suatu modul mikrokontroller. Oleh karena itu, dibutuhkan suatu perangkat berbasis mikrokontroller yang dapat membantu pengguna untuk menampilkan kondisi dari smartphone seperti adanya pesan masuk atau telepon yang masuk ke smartphone, berukuran kecil dan bisa di implementasikan sesuai dengan pekerjaan pengguna. Dengan menggunakan metode prototipe dalam proses perancangan model sederhana yang dapat mewakili hasil yang sebenarnya nantinya dan metode blackbox untuk pengujian alat ini untuk mengetahui apakah perangkat lunak dan perangkat keras berfungsi dengan benar dan telah sesuai dengan yang diharapkan. Dapat dihasilkan suatu perangkat yang berfungsi sebagai media notifikasi bagi smartphone seperti pesan singkat dan panggilan masuk, dan memiliki interface OLED Display. Hal tersebut dapat membantu pengguna Smartphone dalam kehidupan sehari-hari.
\end{abstract}

Kata kunci : Smartphone, Notifikasi, Arduino

\section{PENDAHULUAN}

Maraknya penggunaan smartphone pada semua kalangan masyarakat membuat meningkatnya tuntutan alat-alat aksesoris untuk smartphone untuk kemudahan dalam penggunaanya. Smartphone yang memiliki fasilitas atau fungsi - fungsi seperti sebuah komputer itulah yang membuat sebagian 
besar kalangan masyarakat menggunakan smartphone, mengirim dan menerima email, sosial media, browsing internet, pemutar musik, kamera dan fitur lainnya. Tetapi fungsi sebagai telepon seluler tidak hilang seperti telepon dan pesan singkat, bahkan lebih baik karena spesifikasi dari smartphone tersebut bisa dibilang tinggi. Seiring dengan hal tersebut para pengguna menjadi berlebihan dalam menggunakan smartphone karena tidak sesuai dengan tempatnya, seperti di tempat umum yang memancing tindakan kejahatan karena harga dari smartphone cukup bernilai, misalkan jika pengguna ditempat umum mengeluarkan smartphone miliknya, dapat memancing para pencopet atau penodong untuk merampas smartphone milik pengguna, kemudian untuk para pengendara sepeda motor saat menggunakan smartphone seperti menulis pesan singkat atau hanya melihat kondisi smartphone saat pengguna berhenti di pinggir jalan, dapat memancing perampasan dari pelaku kriminal yang menggunakan sepeda motor juga, semua itu terjadi karena salah satunya karena kita terkadang memancing tindakan kriminal dengan menunjukkan smartphone walaupun pengguna smartphone tidak menyadarinya. Smartphone milik pengguna yang bernilai itu merupakan sasaran bagi pelaku kriminal. Selain itu saat berkendara juga sangat membahayakan para pengendara jika sambil mengecek kondisi smartphone karena pengendara hanya menggunakan satu tangan untuk mengendarai sepeda motor karena tangan yang satu lagi sedang fokus untuk menggunakan smartphone, dan tak hanya itu. Saat mengeluarkan smartphone untuk melihat kondisinya dari kantong pakaian kita juga cukup menyulitkan apalagi bila pengendara menggunakan sarung tangan.

Selain dari pesatnya penggunaan teknologi smartphone pada masyarakat, ada juga teknologi di bidang mikrokontroller yang dapat dikatakan pesat perkembangannya dalam kehidupan sehari-hari masyarakat, yaitu arduino. Arduino merupakan modul mikrokontroller yang cukup banyak digunakan untuk embedded system, Sistem
Otomasi dan perangkat pintar lainnya. Sistem kendali atau sistem kontrol (control system) adalah suatu alat untuk memerintah dan mengatur keadaan dari suatu sistem. Istilah sistem kendali ini dapat dipraktekkan secara manual untuk mengendalikan peralatan rumah secara otomatis (home automation) misalnya pintu dan jendela, ada juga yang dapat diaplikasikan pada kendaraan .

Oleh karena itu, dibutuhkan suatu perangkat berbasis mikrokontroller yang dapat membantu pengguna untuk menampilkan kondisi dari smartphone seperti adanya pesan masuk atau telepon yang masuk ke smartphone, berukuran kecil dan bisa di implementasikan sesuai dengan pekerjaan pengguna.

\section{PERMASALAHAN}

Aktifitas para pengguna smartphone terkadang membutuhkan perangkat tambahan untuk menunjang dalam penggunaan smartphone Seperti jika pengguna sedang ditempat umum, mengikuti rapat, ataupun sedang berkendara kendaraan motor. Hal tersebut menjadi kendala tersendiri bagi pengguna karena jika ada pesan masuk atau panggilan masuk berkemungkinan besar tidak diketahui.

\section{LITERATURE REVIEW}

Berikut ini adalah penelitian yang telah dilakukan dan memiliki kolerasi yang searah dengan penelitian yang akan dibahas dalam Tugas Akhir ini diantara lain:

1. Penelitian yang dilakukan oleh Reza Handaru Winasis (2014) yang berjudul "Pemanfaatan Sensor Accelorometer pada Smartphone Android Sebagai Kendali Pagar Rumah Melalui Bluetooth". Penelitian ini mambahas tentang mengendalikan pintu pagar rumah, yang dapat dilakukan dengan memanfaatkan Sensor 
Accelerometer

Dengan

menggunakan aplikasi Android

Sensor Accelerometer mengirimkan

String tertentu kepada mikrokontroller ATmega 8 melalui komunikasi Bluetooth HC-05 untuk membuka pintu pagar rumah.

2. Penelitian Supriyadi dari STMIK RAHARJA Tangerang yang berjudul "Pemanfaatan Teknologi Bluetooth Untuk Indikator Posisi Suatu Benda" tahun 2013. Pada penelitian ini bertujuan memanfaatkan media bluetooth untuk membantu mencari posisi suatu benda.

3. Penelitian yang dilakukan oleh Dhida Restu Giri Madya (2014) yang berjudul "Prototype pengendali pintu dan jendela mobil menggunakan smartphone berbasis atmega 328p di kelurahan Cibogo". Dalam penelitian ini salah satunya membahas tentang komunikasi serial antara arduino dengan smartphone android lewat media Bluetooth.

4. Penelitian yang dilakukan Reza Nursyah Putra (2014) yang berjudul "Prototipe Alat Pembersih Toren Otomatis menggunakan SMS Gateway pada PT. Cahaya Televisi Indonesia". Dalam penelitian ini salah satunya membahas tentang pengambilan data sebuah pesan singkat pada smartphone.

5. Penelitian yang dilakukan Vani Banu Aji (2014) yang berjudul "Alat Penghitung Jumlah Botol menggunakan Sensor Inductive Proximity dengan Kapasitas 1000 Botol per Menit pada Mesin Filling PT. Cola-Cola Ungaran". Pada penelitian ini salah satunya membahas tentang Komunikasi I2C (Inter Intregated Circuit) pada Mikrokontroller.

6. Penelitian yang dilakukan Andy Renauld (2014) yang berjudul "Sistem Notifikasi Antrian Berbasis Android", pada penelitian ini salah satunya membahas sistem notifikasi pada sebuah smartphone android.

Keterkaitan pembahasan dari penelitian - penelitian yang dilakukan sebelumnya pada literature review di atas adalah adanya komunikasi serial melalui bluetooth, komunikasi I2C dan sebuah sistem yang memiliki notifikasi sebuah sms atau pesan singkat.

\section{PEMBAHASAN \\ Flowchart Sistem}

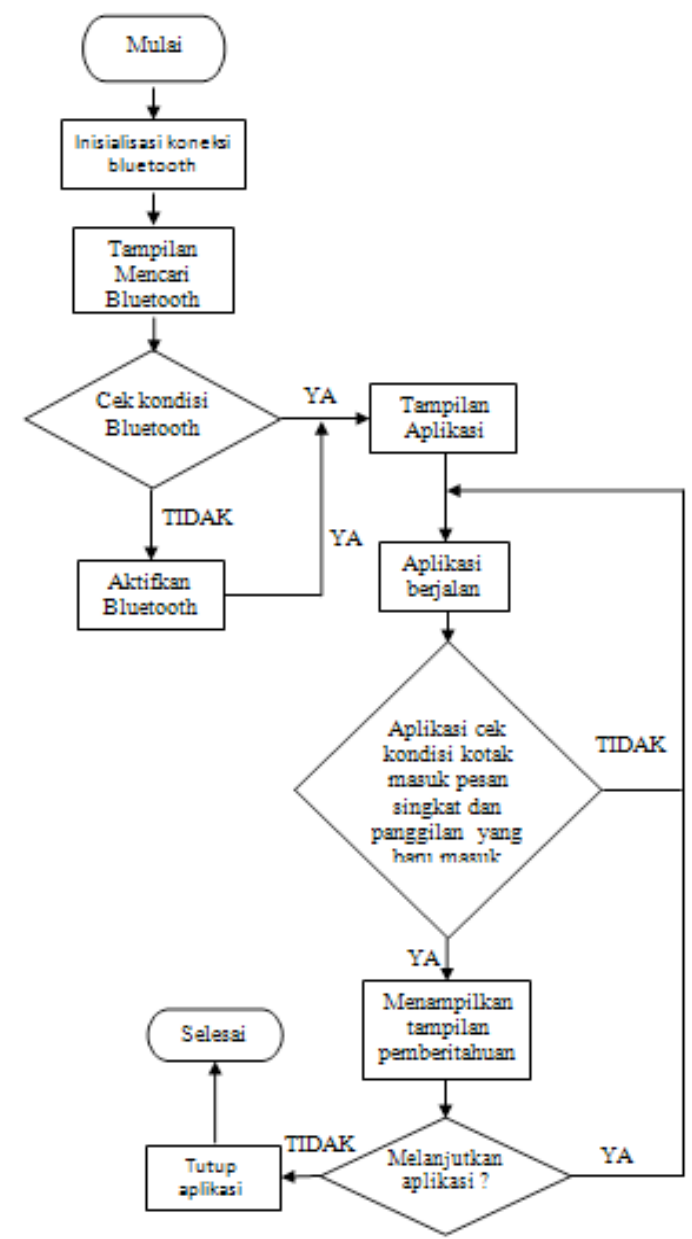

Gambar 1. Flowchart sistem Perangakat Notifikasi Smartphone

\section{Perancangan Hardware}

Perancangan hardware untuk merancang perangkat notifikasi ini menggunakan komponen Arduino Pro Micro sebagai modul untuk melakukan 
proses, Modul Bluetooth HC-05 sebagai media komunikasi serial dengan smartphone, OLED Display sebagai media Interface untuk menampilkan notifikasi pesan masuk dan panggilan masuk, dan Rangkaian catu daya 5 Volt dan 3 Volt sebagai sumber tegangan bagi komponenkomponen tersebut.

\section{Rangkaian Keseluruhan Sistem}

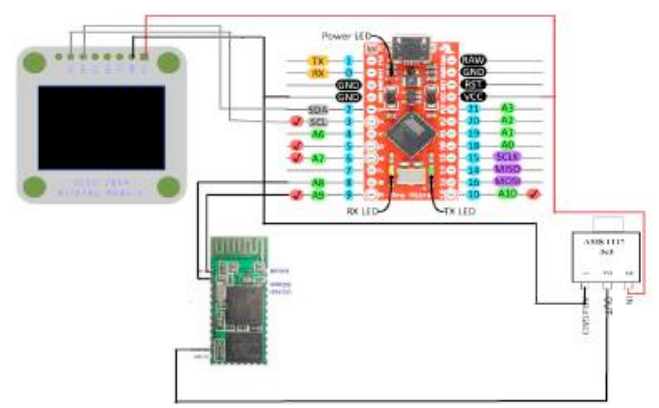

Gambar 2. Diagram Blok Keseluruhan

Rangkaian keseluruhan dari sistem ini merupakan penggabungan dari beberapa rangkaian seperti Arduino Pro Micro, Modul Bluetooth HC-05 dengan komunikasi serial untuk komunikasi antara arduino pro micro dan smartphone, rangkaian Modul OLED Display dengan komunikasi I2C, dan sebagai tambahan IC converter 5 volt ke 3 volt. Tegangan 3 volt digunakan modul bluetooth HC-05.

\section{Arduino pro micro}

Arduino Pro Micro adalah sebuah board mikrokontroller yang menggunakan AT Mega 32u4. Arduino pro micro memiliki pin input/output dimana ada 21 pin digital, 9 pin Analog, 6 pin PWM, pin untuk komunikasi I2C (Inter Intergrated circuit), pin untuk komunikasi UART, dan pin untuk komunikasi SPI. Arduino pro micro mendukung untuk komunikasi lewat USB 2.0, terlihat pada pin ATMega32u4 yang dimiliki terdapat pin D+ dan D- untuk ke komputer tanpa harus menggunakan IC TTL tambahan seperti jenis arduino lainnnya.

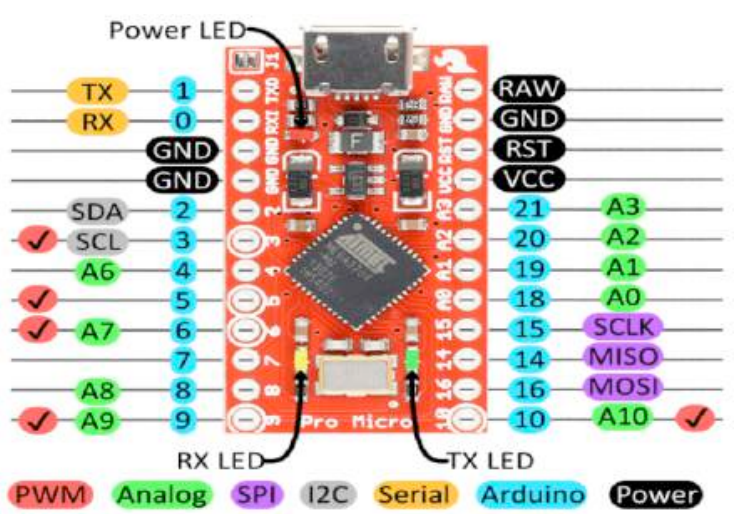

Gambar 3. Arduino Pro Micro

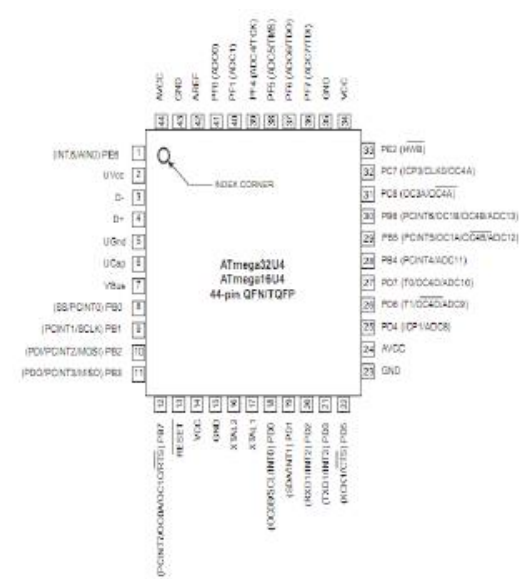

Gambar 4. Konfigurasi pin ATMega32u4

\section{Modul Bluetooth HC-05}

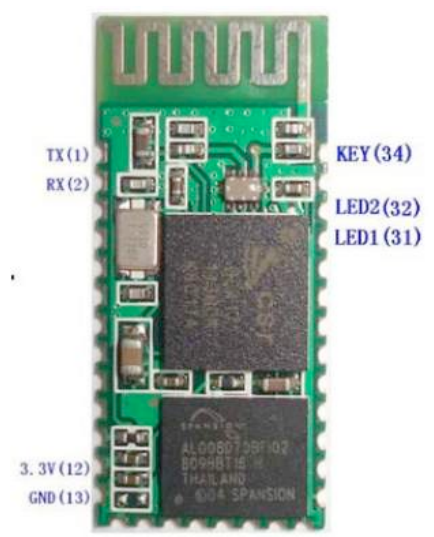

Gambar 5. Tampilan Fisik Modul Bluetooth HC-05

Dalam perancangan Bluetooth ini, menggunakan modul Bluetooth HC-05. Komponen ini berfungsi sebagai media komunikasi antara Arduino Pro Micro dan Smartphone, modul bluetooth HC-05 bekerja dengan sumber tegangan 3 Volt 
yang berasal dari IC Converter yang menurunkan tegangan dari 5 volt menjadi 3 Volt. Modul bluetooth HC-05 memiliki spesifikasi sebagai berikut :

- Bluetooth protocal: Bluetooth Specification v2.0+EDR

- Frequency: $2.4 \mathrm{GHz}$ ISM band

- Modulation: GFSK(Gaussian Frequency Shift Keying)

- Emission power: $\leq 4 \mathrm{dBm}$, Class 2

- Sensitivity: $\leq-84 \mathrm{dBm}$ at $0.1 \%$ BER

- Speed: Asynchronous: 2.1Mbps(Max) / $160 \mathrm{kbps,}$

- Synchronous: 1Mbps/1Mbps

- Security: Authentication and encryption

- Profiles: Bluetooth serial port

- Power supply: +3.3VDC 50mA

- Working temperature: $-20 \sim+75$ Centigrade

- Dimension: $26.9 \mathrm{~mm}$ x $13 \mathrm{~mm}$ x 2.2 $\mathrm{mm}$

\section{OLED Display}

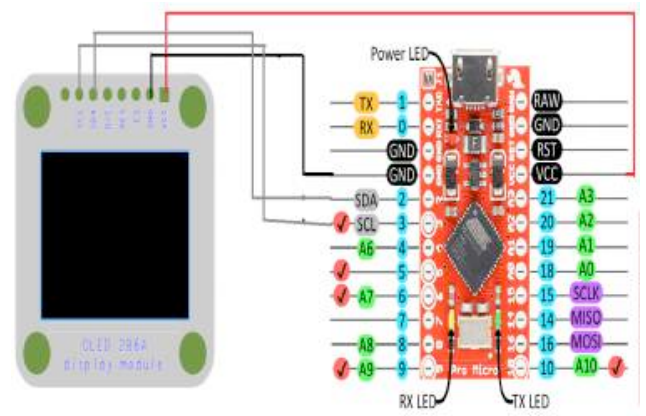

Gambar 6. Rangkaian OLED Display dengan Arduino Pro Micro

Sesuai gambar 6. pin - pin yang dimiliki modul OLED Display disambungkan ke pin untuk komunikasi I2C yang dimiliki arduino pro micro, berikut tabel dari pin yang digunakan dan penjelasannya.

\begin{tabular}{|l|l|l|}
\hline $\begin{array}{l}\text { Pin OLED } \\
\text { Display }\end{array}$ & $\begin{array}{l}\text { Pin Arduino } \\
\text { Pro Micro }\end{array}$ & Penjelasan \\
\hline Pin SDA & Pin 2 & $\begin{array}{l}\text { Berfungsi sebagai } \\
\text { pin penerima dan } \\
\text { pengirim data } \\
\text { dengan } \\
\text { komunikasi I2C }\end{array}$ \\
\hline
\end{tabular}

\begin{tabular}{|l|l|l|}
\hline & & $\begin{array}{l}\text { bagi Arduino Pro } \\
\text { Micro }\end{array}$ \\
\hline Pin SCL & Pin 3 & $\begin{array}{l}\text { Berfungsi sebagai } \\
\text { pin clock bagi } \\
\text { komunikasi I2C } \\
\text { antara OLED } \\
\text { Display dan } \\
\text { Arduino Pro } \\
\text { Micro }\end{array}$ \\
\hline Pin VCC & Pin VCC & $\begin{array}{l}\text { Berfungsi sebagai } \\
\text { sumber tegangan } \\
\text { bagi modul } \\
\text { bluetooth }\end{array}$ \\
\hline Pin GND & Pin GND & $\begin{array}{l}\text { Berfungsi sebagai } \\
\text { ground bagi } \\
\text { modul bluetooth }\end{array}$ \\
\hline
\end{tabular}

Tabe1 1. Konfigurasi Pin arduino pro micro dan Modul bluetooth

\section{Rangkaian Catu Daya}

Agar alat yang di rancang dapat bekerja sesuai dengan fungsinya, maka diperlukan sumber tegangan listrik sebagai catu daya. Perangkat ini menggunakan catu daya yang merubah tegangan bolak-balik (AC) menjadi tegangan searah (DC). Rangkaian catu daya yang digunakan mendapatkan sumber tegangan dari PLN sebesar 220V AC. Tegangan tersebut kemudian diturunkan menjadi 7,5 AC melalui trafo penurun tegangan (step down).

Tegangan 7,5 AC tersebut kemudian diserahkan menjadi tegangan DC oleh dioda bridge. Keluaran dari diode bridge ini kemudian masuk ke kapasitor yang bertujuan untuk mengurangi noise pada tegangan DC. Agar output 7,5 V DC menjadi $5 \mathrm{~V}$ DC maka tegangan $7,5 \mathrm{~V}$ DC dihubungkan ke rangkaian regulator LM7805.

Pada rangkaian catu daya ini akan digunakan untuk memberikan tegangan kerja pada Arduino Pro micro sebesar 5V DC.

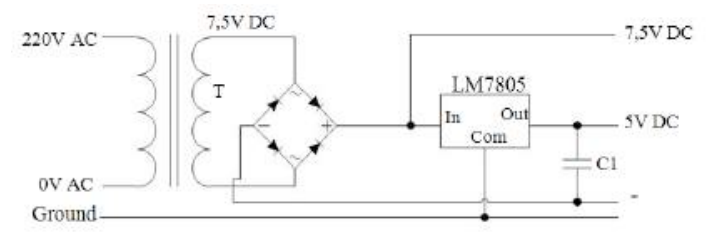

Gambar 7. Rangkaian Catu Daya 5 Volt 
Selain catu daya atau sumber tegangan 5 volt, pada perangkat ini juga dibutuhkan tegangan 3 volt untuk Modul Bluetooth. Sehingga tegangan 5 volt yang ada harus diturunkan menjadi 3 volt. Rangkaian catu daya untuk menurunkan 5 volt menjadi 3 Volt DC menggunakan IC Regulator AMS 1117 3V, rangkaian dapat dilihat pada gambar dibawah ini:

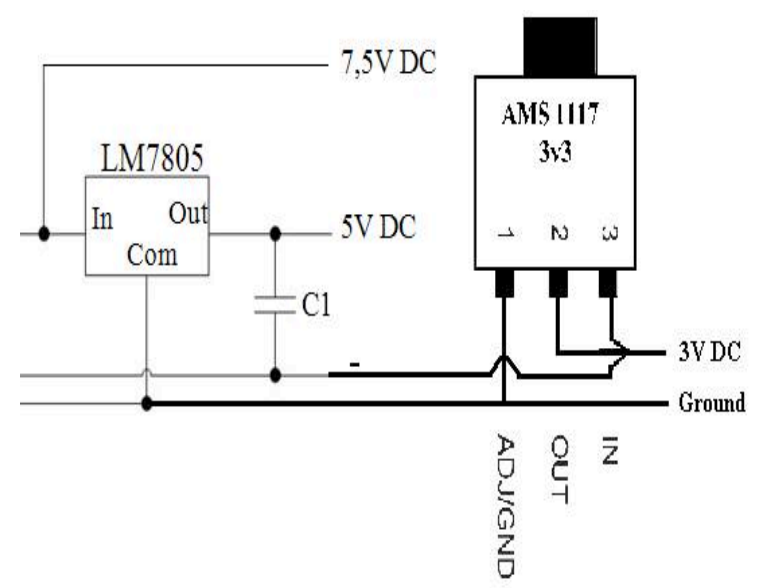

Gambar 8. Rangkaian Catu daya 3 Volt

\section{Komunikasi I2C (Inter Intergrated Circuit)}

Antarmuka serial 2 kabel (TWI) sangat ideal untuk diterapkan pada aplikasi menggunakan mikrokontroller. Protokol ini mengizinkan desain sistem untuk saling berkoneksi sampai 128 piranti yang berlainan menggunakan hanya 2 jalur dua arah, satu untuk clock (SCL) dan satunya untuk data (SDA). Perangkat keras eksternal yang dibutuhkan untuk mengimplementasikan jaringan ini adalah resistor pull-up tunggal untuk setiap jalur bus TWI. Semua piranti dikoneksikan ke bus tersebut mempunyai alamat mandiri, dan mekanisme pengaturan bus yang kemungkinan bertabrakan dalam protokol TWI akibat memiliki jalur yang sama untuk semua piranti. Gambar koneksi antarpiranti dalam protokol TWI di tunjukkan pada gambar .

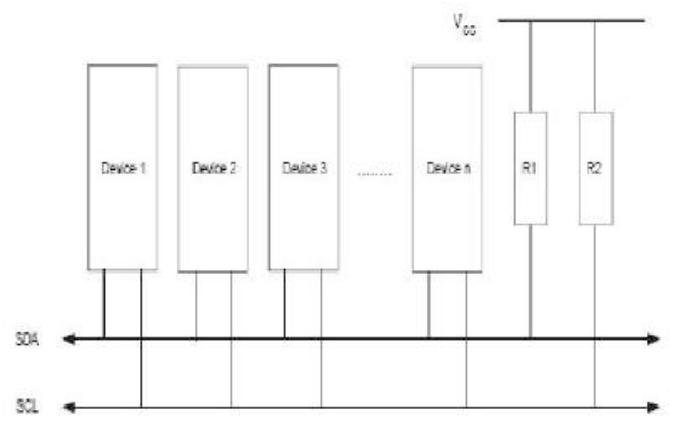

\section{Gambar 9. Diagram koneksi antarpiranti dalam protokol TWI}

Terlihat pada gambar desain protokol perangkat kerasnya sangat mendukung fleksibilitas sistem. Saat ini desain sistem elektronik dan komputer dituntut untuk semakin ringkas dan fleksibel, di mana ukuran fisik IC semakin diperkecil dan jumlah pin diminimalkan dengan tetap menjaga fleksibilitas dan kompabilitas IC sehingga mudah untuk digunakan dalam berbagai keperluan desain yang berbeda. Banyak perusahaan semikonduktor yang berusaha mengembangkan cara baru komunikasi antar-IC yang lebih mendukung terhadap keinginan tersebut sebagai alternatif dari hubungan antar-IC secara paralel (parallel bus) yang sudah dikenal luas. Salah satu metode yang telah matang dan dipakai secara luas adalah I2C, singkatan dari Inter Intergrated Circuit bus yang dikembangkan oleh Philips Semiconduktor sejak tahun 1992, dengan konsep dasar komunikasi 2 arah antar-IC dan/atau antar sistem secara serial menggunakan 2 kabel.

Setiap IC yang terhubung dalam I2C memiliki alamat yang unik yang dapat diakses secara perangkat keras dengan protokol master/slave yag sederhana, dan mampu mengakomodasikan multi-master. I2C merupakan bus serial dengan orientasi data 8 bit, komunikasi 2 arah, dengan kecepatan transfer data sampai 100Kbit/s pada mode standar dan 3,4 Mbit/s pada mode kecepatan tinggi. Jumlah IC yang dapat dihubungkan pada I2C bus hanya dibatasi oleh kapasitas beban pada bus, yaitu maksimum $400 \mathrm{pF}$. Keuntungan yang 
didapat dengan menggunakan I2C antara lain :

- Meminimalkan jalur hubungan antar-IC

- Menghemat luasan PCB yang dibutuhkan.

- Membuat sistem yang didesain berorientasi software (mudah diekspan dan di upgrade).

- Membuat sistem yang didesain menjadi standar sehingga dapat dihubungkan dengan sistem lain yang juga menggunakan bus I2C.

\section{Perancangan software}

\section{Pemrograman Basic 4 Android}

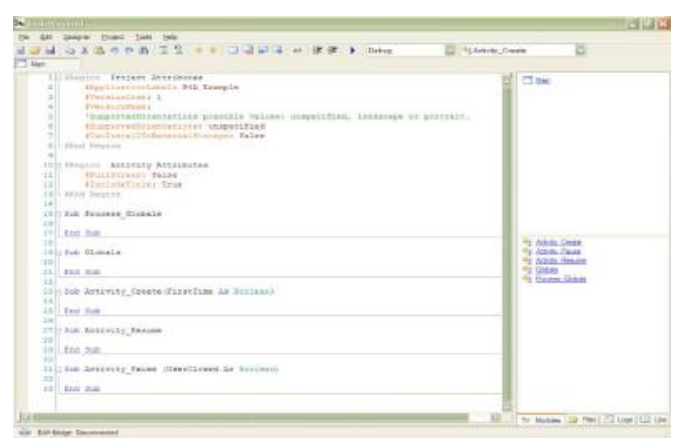

Gambar 10. Tampilan IDE Basic 4 Android

Basic4android adalah development tool sederhana yang powerful untuk membangun aplikasi Android. Bahasa Basic4android mirip dengan bahasa Visual Basic dengan tambahan dukungan untuk objek. Aplikasi Android (APK) yang dicompile oleh Basic4Android adalah aplikasi Android native/asli dan tidak ada extra runtime seperti di Visual Basic yang ketergantungan file msvbvm60.dll, yang pasti aplikasi yang dicompile oleh Basic4Android adalah NO DEPENDENCIES (tidak ketergantungan file oleh lain). IDE Basic4Android hanya fokus pada development Android.

Basic4Android termasuk designer GUI untuk aplikasi Android yang powerful dengan dukungan Built -in untuk multiple screens dan orientations, serta tidak dibutuhkan lagi penulisan XML yang rumit, dapat di develop dan debug dengan Emulator Android atau dengan real device (koneksi ke USB atau melalui local network).

Pemrograman bahasa Basic4Android yang digunakan ini berfungsi untuk mengambil data notifikasi pesan singkat dan panggilan masuk pada smartphone, memprosesnya dan mengirim kembali data tersebut ke Arduino Pro Micro melalui Bluetooth

\section{Arduino IDE}

Untuk Memprogram Mikrokontroller ATMega32u4 atau Arduino Pro Micro dibutuhkan software Arduino IDE(Integrated Development Environment) karena software ini mudah dalam membuat fungsi-fungsi logika dasar mikrokontroller dan sangat mudah di mengerti karena menggunakan bahasa $\mathrm{C}$, selain Software Arduino IDE untuk memasukkan program kedalam sebuah mikrokontroler ATMega32u4, dibutuhkan Driver USB, IDE Arduino 1.0.3 dan Ardunio Pro Micro agar program yang dibuat dapat berjalan di dalam mikrokontroler. Program yang dibuat pada arduino IDE ini berfungsi untuk menerima data dari smartphone dan mengolahnya apakah data tersebut pesan masuk baru atau panggilan masuk, jika ada data yang masuk Arduino pro Micro akan menampilkan tampilan pesan masuk atau panggilan masuk yang baru pada OLED Display.

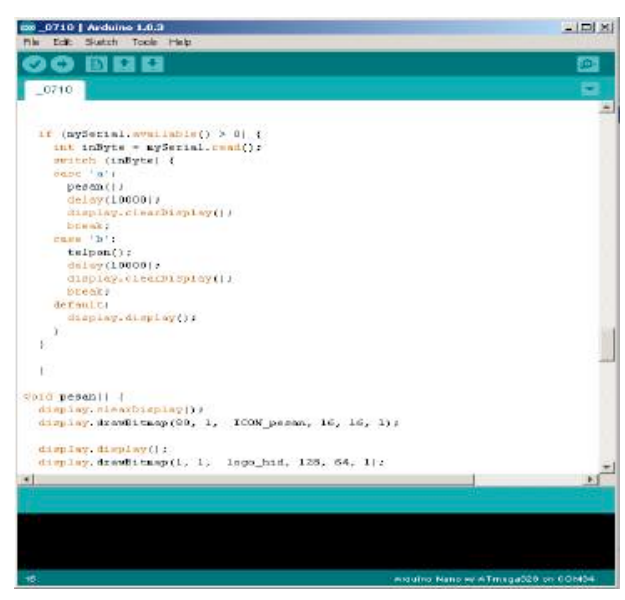

Gambar 11. Arduino IDE 


\section{Uji Coba Modul Bluetooth HC-05}

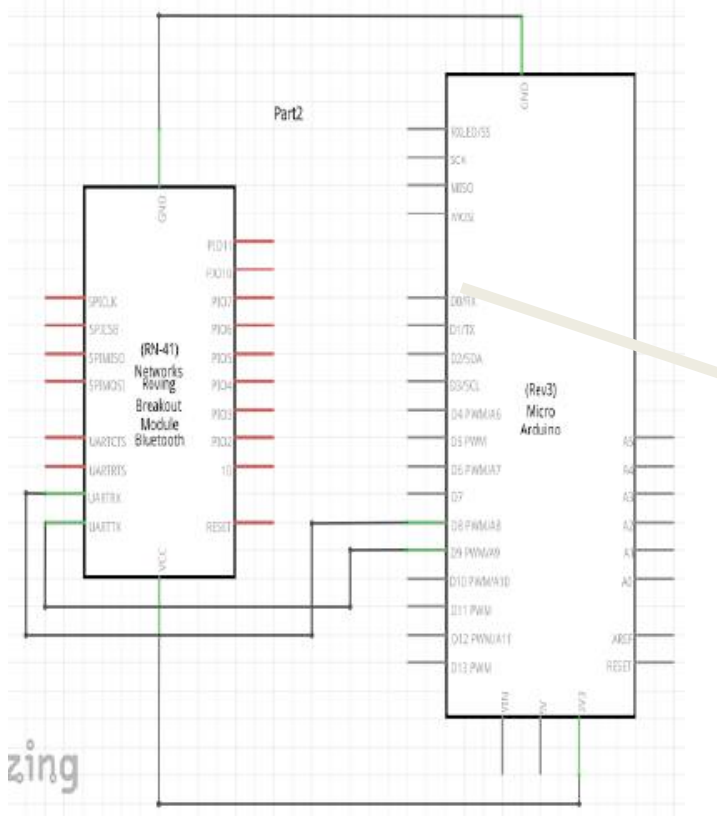

Gambar 12. Rangkaian Modul bluetooth dengan Arduino Pro Micro

Uji coba yang dilakukan pada modul bluetooth terdapat beberapa pin yang harus dihubungkan antara Modul bluetooth dan Arduino Pro Micro, berikut pin - pin yang harus terhubung :

\begin{tabular}{|c|c|c|}
\hline $\begin{array}{c}\text { Pin Modul } \\
\text { bluetooth } \\
\text { HC-05 }\end{array}$ & $\begin{array}{c}\text { Pin } \\
\text { Proino } \\
\text { Micro }\end{array}$ & \multicolumn{1}{|c|}{ Penjelasan } \\
\hline Pin TXD & Pin 9 & $\begin{array}{l}\text { Berfungsi sebagai } \\
\text { pin penerima data } \\
\text { komunikasi serial } \\
\text { bagi Arduino Pro } \\
\text { Micro }\end{array}$ \\
\hline Pin RXD & Pin 8 & $\begin{array}{l}\text { Berfungsi sebagai } \\
\text { pin penerima data } \\
\text { komunikasi serial } \\
\text { bagi Arduino Pro } \\
\text { Micro }\end{array}$ \\
\hline Pin VCC & $\begin{array}{l}\text { Pin } \\
\text { VCC }\end{array}$ & $\begin{array}{l}\text { Berfungsi sebagai } \\
\text { sumber tegangan } \\
\text { bagi modul } \\
\text { bluetooth }\end{array}$ \\
\hline Pin GND & $\begin{array}{l}\text { Pin } \\
\text { GND }\end{array}$ & $\begin{array}{l}\text { Berfungsi sebagai } \\
\text { ground bagi } \\
\text { modul bluetooth }\end{array}$ \\
\hline
\end{tabular}

Tabel 2. Konfigurasi Pin arduino pro micro dan Modul bluetooth
Berdasarkan pin - pin yang harus dihubungkan agar modul bluetooth dapat bekerja, gambar 13. dibawah merupakan hasilnya dari pin yang dihubungkan. Dan ditunjukkan dengan tanda panah untuk modul bluetoothnya.

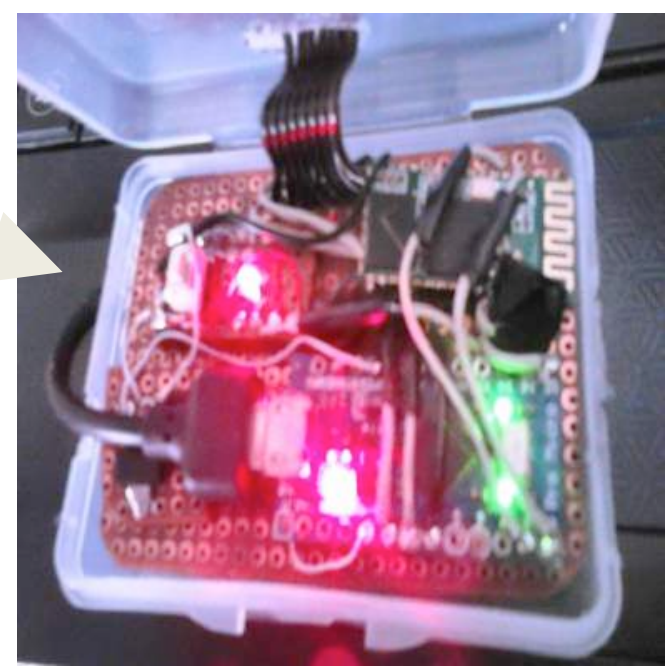

Gambar 13. Rangkaian Modul Bluetooth dengan Arduino Pro Micro

Dengan menyalanya lampu LED indikator pada modul bluetooth, koneksi bluetooh pun dapat terdeteksi pada smartphone seperti pada gambar dibawah dengan nama HC-05.

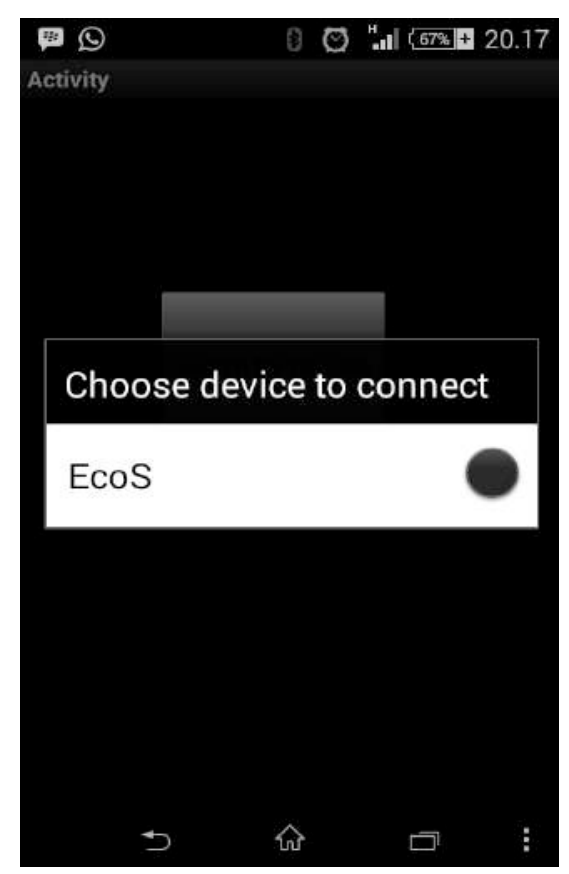

Gambar 14. Tampilan bluetooth terdeteksi Smartphone 


\section{Uji Coba Modul OLED Display}

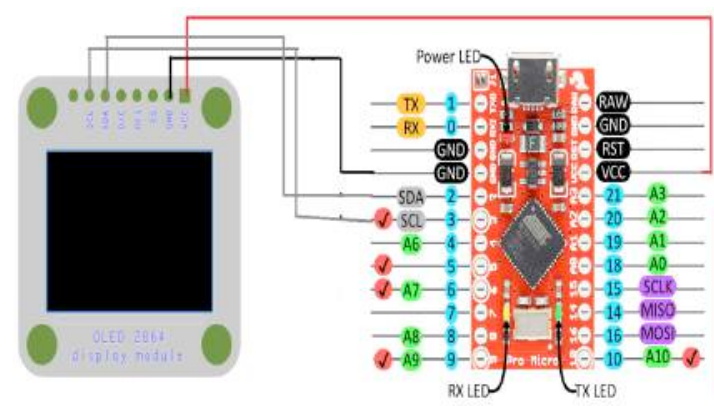

Gambar 15. Rangkaian skematik Modul OLED Display dengan Arduino Pro Micro

Uji coba yang dilakukan pada modul bluetooth terdapat beberapa pin yang harus dihubungkan antara Modul bluetooth dan Arduino Pro Micro, berikut pin - pin yang harus terhubung :

\begin{tabular}{|c|c|c|}
\hline $\begin{array}{c}\text { Pin OLED } \\
\text { Display }\end{array}$ & $\begin{array}{c}\text { Prduino } \\
\text { Pro } \\
\text { Micro }\end{array}$ & \multicolumn{1}{c|}{ Penjelasan } \\
\hline Pin SDA & Pin 2 & $\begin{array}{l}\text { Berfungsi sebagai pin } \\
\text { penerima dan pengirim } \\
\text { data dengan } \\
\text { komunikasi I2C bagi } \\
\text { Arduino Pro Micro }\end{array}$ \\
\hline Pin SCL & Pin 3 & $\begin{array}{l}\text { Berfungsi sebagai pin } \\
\text { clock bagi komunikasi } \\
\text { I2C antara OLED } \\
\text { Display dan Arduino } \\
\text { Pro Micro }\end{array}$ \\
\hline Pin VCC & Pin VCC & $\begin{array}{l}\text { Berfungsi sebagai } \\
\text { sumber tegangan bagi } \\
\text { modul bluetooth }\end{array}$ \\
\hline Pin & $\begin{array}{l}\text { GND } \\
\text { ground bagi modul } \\
\text { bluetooth }\end{array}$ \\
\hline
\end{tabular}

\section{Tabel 3. Konfigurasi Pin Arduino Pro} Micro dan Modul OLED Display

Berdasarkan pin - pin yang harus dihubungkan agar modul OLED Display dapat bekerja sesuai fungsinya. Gambar dibawah ini merupakan hasilnya dari pin yang dihubungkan. Dan ditunjukkan dengan tanda panah untuk modul OLED Display.

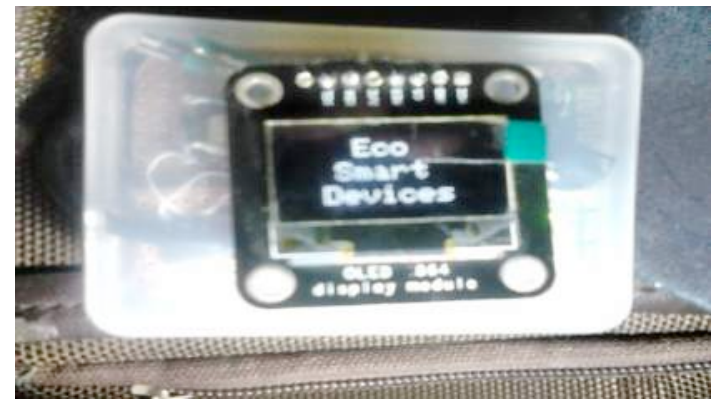

Gambar 16. Hasil Tampilan OLED Display

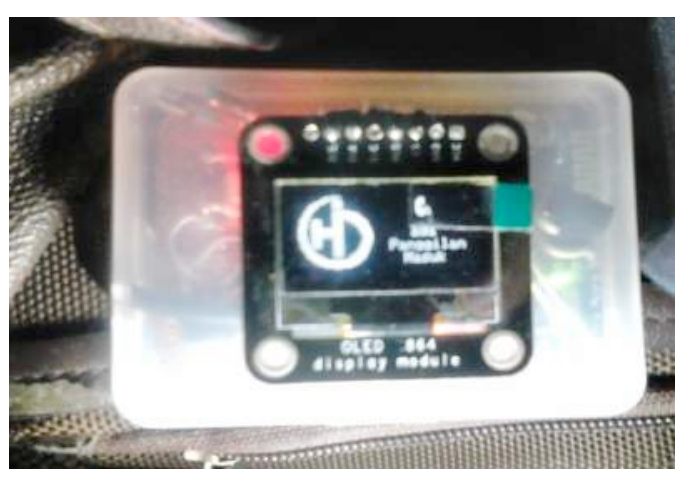

Gambar 17. Hasil Tampilan ada Panggilan masuk

\section{KESIMPULAN}

Kesimpulan yang dapat diambil adalah sebagai berikut :

1. Aplikasi android dapat mengambil data pemberitahuan pesan singkat dan panggilan masuk ke smartphone.

2. Perangkat berbasis Arduino Pro Micro mampu menjadi media antarmuka menggunakan OLED Display.

3. Perangkat notifikasi dapat terhubung dengan smartphone melalui bluetooth, sehingga perangkat dapat langsung digunakan oleh pengguna.

\section{DAFTAR PUSTAKA}

1. Siddiq,Asep Jafar 2012. "Pengujian Perangkat Lunak dengan Metode Black Box Pada Proses Pra 
Registrasi User Via

Website",Makalah,halaman:4

2. Simarmata, Janner.2010.

"RekayasaPeerangkatLunak".

Yogyakarta: Andi Offset

3. Sulindawati dan Muhammad Fathoni.2010. "Pengantar Analisa Sistem Jurnal SAINTIKOM Vol.9,No.2 Agustus 2010:2-19.

4. http://arduino.cc/en/Main/arduinoBo ardMicro, diakses pada tanggal 11 Desember 2014

5. http://www.adafruit.com/datasheets/ UG-2864HSWEG01.pdf, pada tanggal 11 Desember 2014

6. http://www.adafruit.com/datasheets/ SSD1306.pdf, pada tanggal 11 Desember 2014

7. http://www.alldatasheet.com/datash eetpdf/pdf/3042/MOTOROLA/HC05.h tml, pada tanggal 11 Desember 2014

8. http://basic4ppc.com/android/why.h tml, pada tanggal 11 Desember 2014 